Original article

\title{
Molecular characterization and its antioxidant activity of a newly isolated Streptomyces coelicoflavus BC 01 from mangrove soil
}

\author{
Kothagorla Venkata Raghava Rao*, Tamanam Raghava Rao \\ Department of Biochemistry, Andhra University, Visakhapatnam 530003, Andhra Pradesh, India
}

\section{A R T I C L E I N F O}

\section{Article history:}

Received 3 July 2013

Accepted 9 October 2013

Available online 28 December 2013

\section{Keywords:}

Actinomycetes

Antioxidants

Molecular characterization

Phylogenetic tree

Streptomyces

\begin{abstract}
A B S T R A C T
Objective: To isolate and identify the biologically active strain of Streptomyces species from mangrove soil of Visakhapatnam region.

Materials and methods: Actinomycetes are isolated by using starch casein agar media and four potential strains were selected to evaluate the antioxidant activity by using the standard methods DPPH, FRAP and total antioxidant capacity. Further, significant antioxidant activity strain characterized by morphological, physiological, biochemical and molecular characterization.

Results: 20 actinomycetes strains were isolated, among them four active isolates designated as BC $01, \mathrm{BC}$ 02, BC 03 and BC 04 were studied for antioxidant activities. Of these four isolates, BC 01 showed a potent antioxidant activity when compared with other isolates. The morphological, biochemical and molecular characterization of the active isolate BC 01 belongs to the genus Streptomyces species. The phylogenetic tree was constructed and nucleotide blast in search indicated that the strain is $99.7 \%$ similarity with Streptomyces coelicoflavus.

Conclusion: The results of the present investigation proven that actinomycetes isolated from mangroves are potent source of antioxidants. The strain BC 01 exhibited a potential in vitro antioxidant activity; studies of actinomycetes from mangrove soil can be useful in discovery of novel species to get novel drugs.
\end{abstract}

Copyright $\odot$ 2013, InPharm Association, Published by Reed Elsevier India Pvt. Ltd. All rights reserved.

\section{Introduction}

Mangrove ecosystem is an enormous source for isolating the actinomycetes that has the potential for producing the biologically active secondary metabolites. Mangroves are the untouched source for discovering the new actinomycetes. The surroundings of the mangrove environment are brackish and are enormously rich in organic matter due to its numerous microbial enzymatic and metabolic activities. ${ }^{1}$ The mangrove ecosystem is nutritionally resourceful and soils are rich source of new species of Streptomyces, Nocardiopsis and various types of actinomycetes. ${ }^{2}$ Actinomycetes are the major microbes in the soil micro-ecosystem ${ }^{3}$ and are of special interest since they can produce a wide range of biologically active compounds. ${ }^{4}$ They are noteworthy as antibiotic producers, comprising $80 \%$ of all known products and the Streptomyces species are especially regarded as source of antibiotics ${ }^{5}$ and other

\footnotetext{
* Corresponding author. Tel.: +919491553087.

E-mail addresses: kv.raghavarao@yahoo.co.in, raghavarao83@gmail.com (K.V. Raghava Rao).
}

important metabolites, which includes antifungal agents, ${ }^{6}$ antioxidant, $^{7}$ antitumor agents, ${ }^{8}$ antihelmintic agents, ${ }^{9}$ herbicides ${ }^{10}$ respectively.

The present research is focused towards the identification of natural antioxidant producing microorganisms, which serves as safe therapeutics. The melanin that was a natural antioxidant extensively produced from the majority of the Streptomyces species. ${ }^{11}$ Other than melanin, natural antioxidants reported were Protocatechualdehyde from Streptomyces lincolnensis M$20^{12}$ and Surugapyrone A from Streptomyces coelicoflavus USF$6280 .^{13}$

Several studies were carried out to isolate new Streptomyces species from different habitats in order to produce new bioactive metabolites. The study on actinomycetes from mangroves with respect to antioxidant system is meager. Hence, the present study was focused on isolating different Streptomyces species from the mangrove soil in and around Visakhapatnam, Andhra Pradesh, India and to evaluate the antioxidant potential of the four isolates. The best isolate was further characterized by molecular studies to determine its taxon. 


\section{Materials and methods}

\subsection{Sample collection}

The soil sample was collected from 6 to $10 \mathrm{~cm}$ depth from mangrove regions in Visakhapatnam, Andhra Pradesh, India. Samples were stored under aseptic conditions until further use.

\subsection{Isolation and characterization of actinomycetes}

The media used for isolation of actinomycetes was starch casein agar media. The soil samples were serially diluted up to $10^{-5}$ and $0.1 \mathrm{ml}$ of the diluted sample were inoculated on the media by spread plate method. Rifampicin $(5 \mu \mathrm{g} / \mathrm{ml})$ and Nystatin $(25 \mu \mathrm{g} / \mathrm{ml})$ were added to the media to evade from contamination. The inoculated plates were incubated at $28{ }^{\circ} \mathrm{C}$ for 2 weeks. The actinomycetes colonies were identified by their chalky, firm and leathery texture. ${ }^{14}$ These colonies were sub cultured and maintained at $4{ }^{\circ} \mathrm{C}$ for further use.

\subsection{Extraction of bioactive compound}

The pure culture of actinomycetes was cultivated by submerged fermentation on $100 \mathrm{ml}$ of production medium, consisting glucose $1 \%$, soya bean meal $1 \%, \mathrm{NaCl} 1 \%$, and $\mathrm{CaCO}_{3} 0.1 \%$ and Incubated at $28{ }^{\circ} \mathrm{C}$ for $96 \mathrm{~h}$ at $180 \mathrm{rpm}$ on a rotary shaker. After completion of fermentation, the broth was centrifuged and the supernatant was taken in a separating funnel mixed with ethyl acetate by vigorous shaking and kept without any disturbance for $1 \mathrm{~h}$. The ethyl acetate phase that contains bioactive compound was separated under reduced vacuum. The obtained residue was used to evaluate antioxidant activity.

\subsection{Assay of $\mathrm{DPPH}(1,1$, diphenyl-2-picryl hydrazyl) scavenging activity}

The free radical scavenging activity was determined by the method of DPPH with some modifications. ${ }^{15}$ Different concentration $(5,10,15 \& 20 \mu \mathrm{g} / \mathrm{ml})$ of above residual extracts were dissolved in methanol and taken in test tubes separately. Ascorbic acid was used as a reference standard. DPPH $0.004 \%$ was freshly prepared in methanol. DPPH (2 ml) was added to each tube containing different concentrations of extracts $(1 \mathrm{ml})$ and of standard solution $(1 \mathrm{ml})$. It was shaken vigorously. They were then allowed to stand for $30 \mathrm{~min}$ for room temperature in dark place. The control was prepared without any extracts. Methanol was used for base line corrections and absorbance (OD) of sample was measured at $517 \mathrm{~nm}$. The below formula was used to interpret the value of the sample.

$$
\begin{aligned}
\% \text { Radical Scavenging Activity }= & {[\text { (control O.D }} \\
& - \text { sample O.D }) / \text { control O.D }] \\
& \times 100 .
\end{aligned}
$$

\subsection{Ferric reducing antioxidant power assay (FRAP)}

FRAP assay was carried out according to the method of Benzie \& Strain. ${ }^{16}$ The FRAP reagent was prepared by mixing $300 \mathrm{mM}$ acetate buffer ( $\mathrm{pH} 3.6$ ), $10 \mathrm{mM} \mathrm{TPTZ}$ and $20 \mathrm{mM} \mathrm{FeCl} \cdot 6 \mathrm{H}_{2} \mathrm{O}$ in a ratio of $10: 1: 1$, at $37^{\circ} \mathrm{C} .1 .5 \mathrm{ml}$ of the FRAP reagent was mixed with $0.5 \mathrm{ml}$ of the sample and the absorbance was measured at $593 \mathrm{~nm}$ after $15 \mathrm{~min}$. The results are expressed in $\mu$ moles $/ \mathrm{ml}$ of ascorbic acid equivalents by calculating from calibration curve.

\subsection{Determination of total antioxidant capacity}

The total antioxidant capacity was evaluated by the phosphomolybdenum method. ${ }^{17} 0.1 \mathrm{ml}$ of sample was taken in methanol, combined with $1.9 \mathrm{ml}$ of reagent solution (0.6M sulfuric acid, $28 \mathrm{mM}$ sodium phosphate, and $4 \mathrm{mM}$ ammonium molybdate). The tubes were capped and incubated at $95{ }^{\circ} \mathrm{C}$ for $90 \mathrm{~min}$. After the samples were cooled to room temperature, the absorbance was measured at $695 \mathrm{~nm}$ against a blank. Ascorbic acid equivalents were calculated using standard graph of ascorbic acid and values are expressed as ascorbic acid equivalents in $\mu \mathrm{g} / \mathrm{mL}$ of extract.

\subsection{Characterization of potent actinomycetes strain}

The morphological, physiological, cultural and biochemical characteristics of the potent actinomycetes strain were studied. The morphology and the color of spore mass were identified by using optical microscope at $1000 \times$ magnification. The utilization of carbon sources and physiological characterization such as effect of temperature, $\mathrm{pH}, \mathrm{NaCl}$ concentrations $(2,5,7,10,12 \% \mathrm{w} / \mathrm{v})$ were performed. For scanning electron microscope (SEM) the samples were fixed to SEM stubs using carbon tape followed by thin coating with platinum and examined with JEOL; JSM-6610LV scanning electron microscope.

\subsection{Molecular characterization}

The genomic DNA of strain BC 01 was isolated and amplified by PCR with forward primer 8-27f and reverse primer 1500r as described by Mayilraj. ${ }^{18}$ The amplified DNA fragment was separated and purified by using a gel extraction kit and the purified PCR product was sequenced. The $16 \mathrm{~S}$ rRNA gene sequence of strain BC 01 generated in this work (1379 bases) was aligned. A sequence similarity search was performed using GenBank BLASTN,${ }^{19}$ the sequences of closely related taxa were retrieved and aligned using the program CLUSTAL_ $\mathrm{X}^{20}$ and the alignment was corrected manually. A phylogenetic tree was constructed by using the neighbor-joining method $^{21}$ and distances between the sequences were calculated using Kimura's two-parameter model. ${ }^{22}$ The topology of the phylogenetic tree was evaluated by the bootstrap resampling method ${ }^{23}$ with 1000 replicates. Kitasatospora sampliensis MTCC 6546T (AY260167) was used as an out group. The guanine and cytosine $(\mathrm{G}+\mathrm{C})$ content was determined by thermal denaturation method. ${ }^{24}$

\subsection{GC FAME analysis}

The potent strain BC 01 was grown on tryptic soya broth (TSB) medium at $30^{\circ} \mathrm{C}$ for 3 days for the identification of the cellular fatty acids. The fatty acids methyl esters (FAME) were obtained by saponification, methylation, extraction and washing of the freshly grown culture. The sample was analyzed by Hewlett Packard 5890A gas chromatography equipped with HP7673A auto sampler and a flame-ionization detector fitted with a $5 \%$ phenyl methyl silicon column (A25 m $\times 0.2 \mathrm{~mm}$ ). The temperature of the oven was $170^{\circ} \mathrm{C}-270^{\circ} \mathrm{C}$ increasing at a rate of $5^{\circ} \mathrm{C}$ per min and the injectionport temperature was $300{ }^{\circ} \mathrm{C}$ with hydrogen as carrier gas and nitrogen as make up gas. Fatty acid profiles were compared with profiles of the Sherlock Microbial Identification System (MIS) Software. $^{25}$

\subsection{Statistical analysis}

All investigations were conducted in triplicate and the attained data was exposed to one way ANOVA by using Minitab ver 15 and the significance level was 0.05 . 
Table 1

DPPH radical scavenging activity of the four extracts.

\begin{tabular}{lllll}
\hline \% Inhibition & \multicolumn{5}{l}{} \\
\hline $\begin{array}{l}\text { Name of the } \\
\text { extract }\end{array}$ & \multicolumn{5}{l}{ Concentration of the extract } \\
\cline { 2 - 5 } & $5 \mu \mathrm{g} / \mathrm{ml}^{\mathrm{a}}$ & $10 \mu \mathrm{g} / \mathrm{ml}^{\mathrm{a}}$ & $15 \mu \mathrm{g} / \mathrm{ml}^{\mathrm{a}}$ & $20 \mu \mathrm{g} / \mathrm{ml}^{\mathrm{a}}$ \\
\hline BC 01 & $56.58 \pm 12.07$ & $61.13 \pm 15.92$ & $65.30 \pm 18.20$ & $68.91 \pm 21.00$ \\
BC 02 & $52.41 \pm 16.76$ & $57.88 \pm 22.47$ & $62.46 \pm 21.62$ & $65.12 \pm 23.00$ \\
BC 03 & $36.83 \pm 4.84$ & $41.15 \pm 1.43$ & $43.82 \pm 2.66$ & $46.41 \pm 3.55$ \\
BC 04 & $37.91 \pm 1.40$ & $43.45 \pm 2.60$ & $47.00 \pm 5.85$ & $53.12 \pm 11.95$ \\
Ascorbic acid & $47.03 \pm 15.90$ & $51.24 \pm 7.31$ & $67.96 \pm 25.69$ & $70.64 \pm 25.07$ \\
& $F=1.61^{@}$ & $F=1.39^{@}$ & $F=1.23^{@}$ & $F=1.13^{@}$ \\
\hline
\end{tabular}

${ }^{@}$ Not significant.

${ }^{\text {a }}$ Each value represents mean \pm SD of three independent experiments.

Table 2

FRAP activity of the four extracts.

\begin{tabular}{lllll}
\hline \multicolumn{4}{l}{ Ascorbic acid equivalents $(\mu$ moles $/ \mathrm{ml})$} \\
\hline $\begin{array}{l}\text { Name of the } \\
\text { extract }\end{array}$ & \multicolumn{4}{l}{ Concentration of the extracts } \\
\cline { 2 - 5 } & $5 \mu \mathrm{g} / \mathrm{ml}^{\mathrm{a}}$ & $10 \mu \mathrm{g} / \mathrm{ml}^{\mathrm{a}}$ & $15 \mu \mathrm{g} / \mathrm{ml}^{\mathrm{a}}$ & $20 \mu \mathrm{g} / \mathrm{ml}^{\mathrm{a}}$ \\
\hline BC 01 & $64.00 \pm 14.00$ & $68.67 \pm 11.02$ & $72.00 \pm 13.11$ & $78.00 \pm 15.10$ \\
BC 02 & $55.33 \pm 13.32$ & $60.00 \pm 12.49$ & $63.33 \pm 11.02$ & $68.67 \pm 11.72$ \\
BC 03 & $59.33 \pm 12.06$ & $62.67 \pm 14.19$ & $68.00 \pm 11.14$ & $72.00 \pm 12.00$ \\
BC 04 & $56.00 \pm 8.00$ & $62.67 \pm 9.45$ & $66.00 \pm 9.17$ & $72.00 \pm 10.00$ \\
& $F=0.32^{@}$ & $F=0.28^{@}$ & $F=0.32^{@}$ & $F=0.30^{@}$ \\
\hline
\end{tabular}

${ }^{\circledR}$ Not significant.

a Each value represents mean \pm SD of three independent experiments.

\section{Results}

In the present study 20 actinomycetes strains were isolated from mangrove soil, Visakhapatnam, India. Among them four potent strains were designated as BC 01, BC 02, BC 03 and BC 04 were subjected to in vitro antioxidant activity. Compounds with high concentration exhibited highest rate of antioxidant capacity followed to the least.

DPPH is a stable free radical accepts protons from the antioxidant source and shows a decreasing absorption. In the present study, all the four extracts (BC 01-BC 04) were evaluated for their DPPH scavenging assay. It was witnessed that all the four extracts (BC 01-BC 04) showed an effective DPPH radical scavenging activity but $B C 01$ showed significant levels $(68.91 \pm 21.00)$ (Table 1$)$ which were comparable with remaining three isolates. The DPPH activity was determined in percentage of inhibition.

FRAP a method used to detect the reducing potential of an antioxidant source. Tripyridyltriazine (ferric form) combines with antioxidant source results in the formation of a blue color complex (ferrous form) which was measured at $593 \mathrm{~nm}$. The amount of iron reduced can be correlated with the amount of antioxidant capacity of isolates (Table 2). Activity was expressed in terms of ascorbic acid

Table 3

The total antioxidant capacity of the four extracts.

\begin{tabular}{lllll}
\hline \multicolumn{4}{l}{ Ascorbic acid equivalents $(\mu \mathrm{g} / \mathrm{ml})$} \\
\hline $\begin{array}{lllll}\text { Name of the } \\
\text { extract }\end{array}$ & \multicolumn{4}{l}{ Concentration of the extract } \\
\cline { 2 - 5 } & $5 \mu \mathrm{g} / \mathrm{ml}^{\mathrm{a}}$ & $10 \mu \mathrm{g} / \mathrm{ml}^{\mathrm{a}}$ & $15 \mu \mathrm{g} / \mathrm{ml}^{\mathrm{a}}$ & $20 \mu \mathrm{g} / \mathrm{ml}^{\mathrm{a}}$ \\
\hline BC 01 & $75.667 \pm 3.512$ & $82.333 \pm 2.517$ & $89.667 \pm 2.082$ & $93.33 \pm 2.52$ \\
BC 02 & $63.333 \pm 3.215$ & $69.000 \pm 1.732$ & $77.000 \pm 4.000$ & $99.33 \pm 3.51$ \\
BC 03 & $62.667 \pm 3.512$ & $72.333 \pm 1.528$ & $83.333 \pm 7.371$ & $97.67 \pm 2.08$ \\
BC 04 & $67.000 \pm 2.000$ & $72.000 \pm 4.000$ & $76.667 \pm 2.082$ & $83.33 \pm 2.52$ \\
& $F=11.00^{*}$ & $F=14.63^{*}$ & $F=5.75^{*}$ & $F=21.10^{*}$ \\
\hline
\end{tabular}

${ }^{*} 5 \%$ level of significance $(p<0.05)$.

a Each value represents mean \pm SD of three independent experiments.

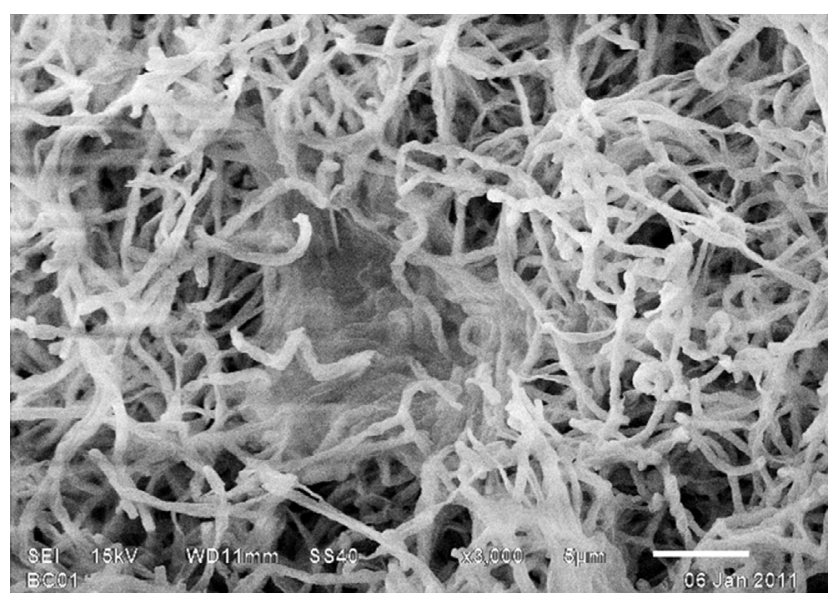

Fig. 1. Scanning electron microscope of the potent actinomycete strain $\mathrm{BC} 01$.

equivalents ( $\mu$ moles $/ \mathrm{ml}$ ). Among all the four extracts the $\mathrm{BC} 01$ showed highest activity (78.00 \pm 15.10$)$ of ascorbic acid equivalents.

Phosphomolebdenum method was used to evaluate the total antioxidant capacity (TAC) which involves the reduction of Mo (VI) to Mo $(\mathrm{V})$ results in the formation of a green colored complex, which shows maximum absorbance at $695 \mathrm{~nm}$. Among all the four extracts, TAC was found to be highest in BC 02 $(99.33 \pm 3.51 \mathrm{l})$ followed by BC $01(93.33 \pm 2.52)$. The total antioxidant capacity of all the four extracts at different concentrations used in this study shows the significant variance $(p<0.05)$, the results are expressed as the $\mu \mathrm{g} / \mathrm{ml}$ of ascorbic acid equivalents and tabulated in Table 3.

Table 4

Morphological and biochemical characteristics of the potent actinomycetes strain BC 01.

\begin{tabular}{|c|c|}
\hline Name of the test & Results \\
\hline Substrate Mycelia on Starch casein agar & White \\
\hline Aerial Mycelia on Starch casein agar & Gray \\
\hline Pigmentation & Nil \\
\hline Spore surface & Smooth \\
\hline Spore bearing aerial hyphae & Flexous \\
\hline Growth at temperature & $25^{\circ}-35^{\circ} \mathrm{C}$ \\
\hline Growth at $\mathrm{pH}$ & $7.2-8.2$ \\
\hline Indole production & + \\
\hline Methyl red & + \\
\hline Voges-Proskauer & + \\
\hline Citrate utilization & + \\
\hline Melanin formation & + \\
\hline Gelatin hydrolysis & + \\
\hline Tyrosine reaction & + \\
\hline $\mathrm{H}_{2} \mathrm{~S}$ production & + \\
\hline Casein hydrolysis & + \\
\hline Starch hydrolysis & + \\
\hline Nitrate reduction & + \\
\hline Urease & - \\
\hline Catalase & + \\
\hline Gelatin & + \\
\hline \multicolumn{2}{|l|}{ Carbon source utilization } \\
\hline Glucose & + \\
\hline Fructose & + \\
\hline Galactose & + \\
\hline Sucrose & - \\
\hline Mannose & + \\
\hline Mannitol & + \\
\hline Sorbitol & + \\
\hline Inositol & + \\
\hline Xylose & - \\
\hline Arabinose & - \\
\hline Glycerol & + \\
\hline
\end{tabular}

+- Positive, -- Negative. 
Table 5

Fatty acid percentage profile of the potent actinomycetes strain BC 01.

\begin{tabular}{lc}
\hline Fatty acid & Percentage (\%) \\
\hline $\mathrm{C}_{11: 0}$ & 0.25 \\
Iso- $_{11: 0}$ & 0.34 \\
$\mathrm{C}_{12: 0}$ & 0.99 \\
Iso- $_{13: 0}$ & 0.19 \\
Iso- $_{14: 0}$ & 2.26 \\
$\mathrm{C}_{14: 1}$ Cis9/Trans9 & 1.04 \\
$\mathrm{C}_{14: 0}$ & 1.13 \\
Iso- $\mathrm{C}_{15: 0}$ & 9.74 \\
Anteiso-C $15: 0$ & 17.80 \\
$\mathrm{C}_{15: 0}$ & 1.65 \\
Iso- $\mathrm{C}_{16: 1} \mathrm{H}$ & 2.63 \\
Iso- $\mathrm{C}_{16: 0}$ & 21.68 \\
$\mathrm{C}_{16: 1}$ Cis 9 & 2.07 \\
$\mathrm{C}_{16: 0}$ & 8.84 \\
$\mathrm{C}_{16: 0} 9$ Methyl & 4.39 \\
Iso- $\mathrm{C}_{17: 0}$ & 5.44 \\
Anteiso- $\mathrm{C}_{17: 0}$ & 11.58 \\
Anteiso- $\mathrm{C}_{17: 1 \mathrm{C}} \mathrm{C}$ & 2.88 \\
$\mathrm{C}_{17: 1}$ Cis 9 & 0.65 \\
Cyclo $_{17: 0}$ & 1.27 \\
$\mathrm{C}_{17: 0}$ & 0.66 \\
Iso- $\mathrm{C}_{17: 02} \mathrm{OH}$ & 0.24 \\
$\mathrm{C}_{18: 0}$ & 0.81 \\
$\mathrm{C}_{19: 1}$ Trans 7 & 0.57 \\
\hline
\end{tabular}

\subsection{Morphological characteristic of potent isolate}

The physiological and morphological observations revealed that the isolated strain had the characteristic features of the genus Streptomyces. The spore was smooth and non-motile; the rod shaped spore chain was borne on aerial mycelium. The aerial mycelia are abundant and developed without fragmentation (Fig. 1). The morphological, biochemical and physiological characteristics of the strain were tabulated in Table 4.

\subsection{GC FAME analysis}

Major cellular fatty acids Iso- $C_{16: 0}(21.68 \%)$ and Anteiso- $C_{15: 0}$ (17.80\%) were identified by using GC FAME analysis (Table 5). Previous results showed that actinomycetes produce saturated and unsaturated fatty acids with branched chain lengths in the range of $\mathrm{C}_{10}-\mathrm{C}_{18} \cdot{ }^{26}$ Our results also showed that the fatty acids obtained are in the range.

\subsection{Molecular characterization and phylogenetic analysis of the potent isolate $B C 01$}

The purity of the genomic DNA was 1.795 and the genomic DNA $\mathrm{G}+\mathrm{C}$ content of the strain BC 01 was $69.7 \mathrm{~mol} \%$. The 16S rRNA gene partial sequence was deposited in NCBI nucleotide database with Accession No JX126485 and the sequence was correlated with genus Streptomyces by using BLASTN. Sequence analysis revealed that the isolated strain showed highest (99.7\%) 16S rRNA gene sequence identity with (a four nucleotide difference out of $1379 \mathrm{nt}$ ) with S. coelicoflavus NBRC 15399(T) of GenBank accession No. AB184650 and the analysis of the sequence confirmed that the strain belongs to the species $S$. coelicoflavus. A phylogenetic tree was reconstructed by using neighbor-joining method (Fig. 2) and the results stipulate that the strain $\mathrm{BC} 01$ closely resembles with the genus S. coelicoflavus NBRC 15399T (AB184650).

By comparing the morphological and biochemical characteristics of the strain BC 01 with the standard literature of S. coelicoflavus ZG0656 ${ }^{27}$ and Streptomyces aurantiacus, ${ }^{28}$ the strain BC 01 was confirmed to belong to $S$. coelicoflavus.

\section{Discussion}

The mangroves involve a massive quantity of novel actinomycetes, which are promising sources of bioactive metabolites. The mangrove environs are huge unexplored zone and are biochemically exceptional for generating a wide range of novel natural products comprises biologically active compounds. Now a days research is focused on the replacement of synthetic antioxidants with a natural one to preclude the side effects caused by synthetic antioxidants. A search is going for screening of a new source to discover natural ones.

DPPH, FRAP and Phosphomolybdenum are the proven methods to evaluate radical scavenging activity. In the present study four isolate extracts ( $\mathrm{BC}$ 01-BC 04) were evaluated for their antioxidant activity. The results showed that four isolates were presenting substantial antioxidant activity, of these BC 01 exhibited potent

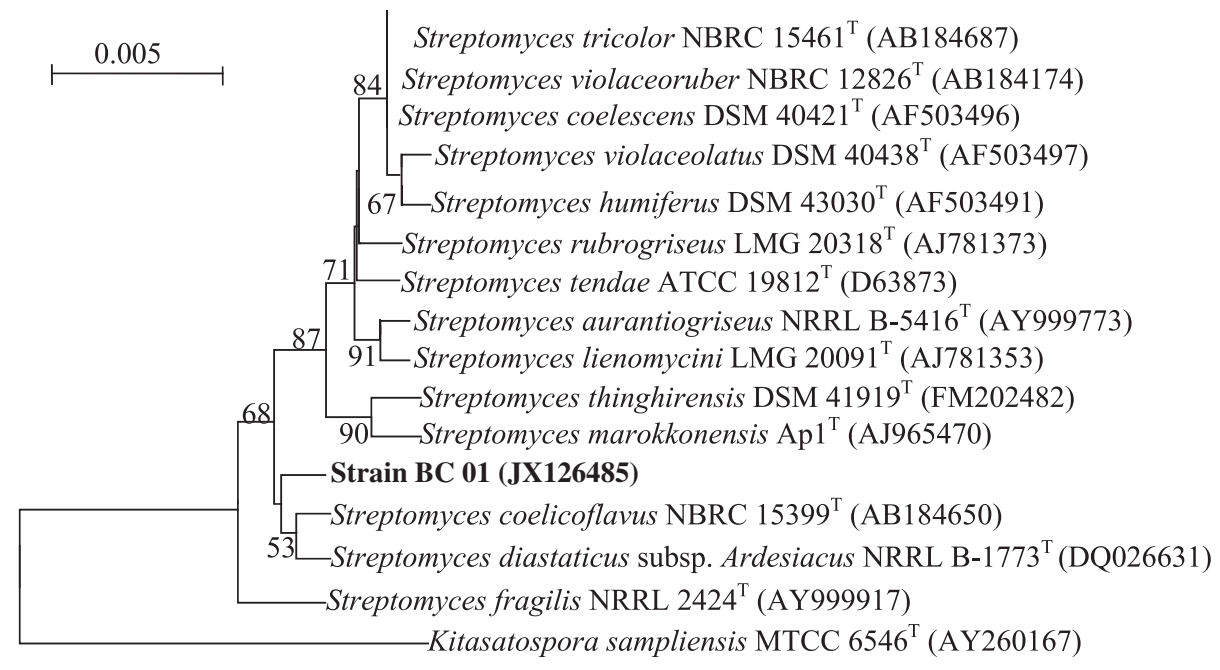

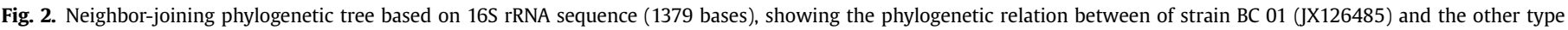

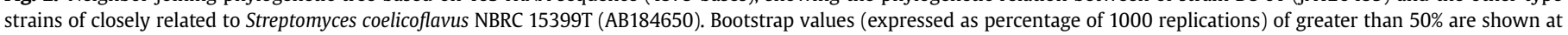
the branch points. Bar 0.005 substitutions per site and Kitasatospora sampliensis MTCC 6546T (AY260167) was used as out group. 
activity. This is the first report of this kind from mangrove ecosystem of Visakhapatnam region. It shows that mangrove soil is also rich in bioactive compounds with high antioxidant activity. Comparable reports with rich source of Streptomyces species were reported in marine environment, a compound 5- $(2,4-$ dimethylbenzyl) pyrrolidin-2-one extracted from marine Streptomyces VITSVK5 spp which exhibited potent antioxidant activity. ${ }^{29}$ Similarly the Streptomyces VITTK3 species showed effective DPPH radical scavenging activity in both extracellular and intracellular metabolites $^{30}$ and also Streptomyces Eri12 isolated from rhizosphere of Rhizoma curcumae Longae was an aspirant from the nature source of antioxidants. ${ }^{31}$

Further studies were carried with BC 01 strain due to its highest antioxidant activity when compared with the other three isolates. The molecular characterization revealed that the strain belongs to the genus Streptomyces and for phylogenetic tree analysis exposes that the strain closely correlated with species $S$. coelicoflavus.

\subsection{Description of Streptomyces coelicoflavus}

The strain is gram-positive, aerobic and non-acid fast. Vegetative hypha is enormously branched, copious and fragmented. After 2 weeks of incubation aerial mycelia was gray to chalky white in starch casein agar media. Smooth and non-motile spores are observed. Glucose, fructose, galactose, glycerol, mannose, mannitol, and sorbitol, are used as carbon sources. Starch, gelatin and casein are hydrolyzed. IMVC tests are positive. The biochemical tests like nitrate reduction, $\mathrm{H}_{2} \mathrm{~S}$ production, catalase, tyrosine and melanin production were positive. The optimum growth of the isolate is $25^{\circ} \mathrm{C}-35^{\circ} \mathrm{C}$ at $\mathrm{pH} 7.0-8.2$. The strain was resistance against antibiotics streptomycin, kanamycin and tetracycline up to $100 \mu \mathrm{g} / \mathrm{ml}$, but rifampicin is $50 \mu \mathrm{g} / \mathrm{ml}$. In the cell wall the leading fatty acids found were Iso- $C_{16: 0}(21.68)$, Anteiso- $C_{15: 0}(17.80)$ and Anteiso$\mathrm{C}_{17: 0}(11.58)$. The guanine and cytosine content of the isolated DNA was found to be $69.7 \mathrm{~mol} \%$. The $16 \mathrm{~S}$ rRNA gene partial sequence was deposited in NCBI nucleotide database with Accession No JX126485.

\section{Conclusion}

The present study was mainly focused on isolation and molecular characterization of potent actinomycetes from mangrove soil. Therefore, we conclude that microbes isolated from mangroves having potent bioactive secondary metabolites. Our results evidenced that the four extracts showed worthy antioxidant activity, which was produced from natural source. Among them, the isolate BC 01 revealed a potential in vitro antioxidant activity equally with the standard reference. The morphological, biochemical, physiological, molecular characterization confirmed that the strain belongs to the species $S$. coelicoflavus. Further, the bioactive compound is to be purified and the structural elucidation of the compound is to be done. The purified compound is to be analyzed for biological activities. The current attempt for isolation and characterization of actinomycetes from mangrove environs will be favorable for the identification of novel antibiotics.

\section{Conflicts of interest}

All authors have none to declare.

\section{Acknowledgment}

The author (K.V. Raghava Rao) gratefully acknowledges the University Grants Commission (UGC), New Delhi, India for providing financial assistance to study this work under Non-SAP scheme.

\section{References}

1. Kizhekkedathu NN, Parukuttyamma P. Mangrove actinomycetes as the source of lignolytic enzymes. Actinomycetologica. 2005;19:40-47.

2. Long H, Xiang W, Zhuang T, Lin P. Microorganism resource of mangrove ecosystems. Chin J Ecol. 2005;24:696-702.

3. Thangapandian V, Ponmurugan P, Ponmurugan K. Actinomycetes diversity in the rhizosphere soils of different medicinal plants in Kolly Hills-Tamil Nadu, India, for secondary metabolite production. Asian J Plant Sci. 2007;6: $66-70$.

4. Bredholt H, Fjaervik E, Jhonsen G, Zotechev SB. Actinomycetes from sediments in the Trondheim Fjord, Norway: diversity and biological activity. J Mar Drugs. 2008;6:12-24.

5. Hopwood DA. Therapeutic treasures from the deep. Nat Chem Biol. 2007:3: 457-458.

6. Thakur D, Yadav A, Gogoi BK, Bora TC. Isolation and screening of Streptomyces in soil of protected forest areas from the states of Assam and Tripura, India, for antimicrobial metabolites. J Med Mycol. 2007:17:242-249.

7. George M, Anjumol A, George G, Mohamed Hatha AA. Distribution and bioactive potential of soil actinomycetes from different ecological habitats. Afr J Microbiol Res. 2012;6:2265-2271.

8. Konishi M, Okuma H, Kawaguchi H. Dynamics new antibiotics with the 1, 5 diyn-3-ene and anthraquinone subunit. Production, isolation and physicochemical properties. J Antibiot. 1991;44:1300-1305.

9. Sanglier JJ, Haag H, Huck TA, Fehr T. Novel bioactive compounds from actinomycetes. Res Microbiol. 1993;144:633-642.

10. Lee HB, Kim CJ, Kim JS, Hong KS, Cho KY. A bleaching herbicidal activity of methoxyhygromycin (MHM) produced by an actinomycete strain Streptomyces sp. 8E-12. Lett Appl Microbiol. 2003;36:387-389.

11. Hewedy MA, Ashour SM. Production of a melanin like pigment by Kluyveromyces marxianus and Streptomyces chibaensis. Aust J Basic Appl Sci. 2009;3: 920-927.

12. Kim Kyoung-Ja, Kim Mi-Ae, Jung Jee-Hyung. Antitumor and antioxidant activity of protocatechualdehyde produced from Streptomyces lincolnensis M-20. Arch Pharm Res. 2008;31:1572-1577.

13. Sugiyama Yasumasa, Oya Akiko, Kudo Takuji, Hirota Akira. Surugapyrone A from Streptomyces coelicoflavus strain USF-6280 as a new DPPH radical-scavenger. J Antibiot. 2010;63:365-369.

14. Jensen PR, Dwight R, Fenical W. Distribution of actinomycetes in near-shore tropical marine sediments. Appl Environ Microbiol. 1991;57:1102-1108.

15. Parasuraman S, Kumar EP, Kumar A, Emerson SF. Free radical scavenging property and diuretic effect of triglize, a polyherbal formulation in experimental models. J Pharmacol Pharmacother. 2010;1:38-41.

16. Benzie I, Strain J. The ferric reducing ability of plasma (FRAP) as a measure of antioxidant power: the FRAP assay. Anal Biochem. 1996;239:70-76.

17. Prieto P, Pineda M, Aguilar M. Spectrophotometric quantitation of antioxidant capacity through the formation of a phosphomolybdenum complex: specific application to the determination of vitamin E. Anal Biochem. 1999;269:337-341.

18. Mayilraj S, Prasad GS, Suresh K, Saini HS, Shivaji S, Chakrabarti T. Planococcus stackebrandtii sp. nov., isolated from a cold desert of the Himalayas, India. Int J Syst Evol Microbiol. 2005;55:91-94.

19. Altschul SF, Madden TL, Schaffer AA, et al. Gapped BLAST and PSI-BLAST: a new generation of protein database search programs. Nucleic Acids Res. 1997;25: 3389-3402.

20. Thompson JD, Gibson TJ, Plewniak F, Jeanmougin F, Higgins DG. The CLUSTAL $\mathrm{X}$ windows interface: flexible strategies for multiple sequence alignment aided by quality analysis tools. Nucleic Acids Res. 1997;25:4876-4882.

21. Saitou N, Nei M. The neighbor-joining method: a new method for reconstructing phylogenetic trees. Mol Biol Evol. 1987:4:406-425.

22. Kimura M. A simple method for estimating evolutionary rates of base substitutions through comparative studies of nucleotide sequence. J Mol Evol. 1980;16:111-120.

23. Felsenstein J. Confidence limits on phylogenies: an approach using the bootstrap. Evolution. 1985;39:783-791.

24. Marmur J, Doty P. Determination of the base composition of deoxyribonucleic acid from its thermal denaturation temperature. $J \mathrm{Mol}$ Biol. 1962; 54:109-118.

25. Sasser M. Identification of Bacteria by Gas Chromatography of Cellular Fatty Acids. MIDI Technical Note 101. Newark, DE: MIDI Inc; 1990.

26. Sobolevskaya MP, Shevchenko LS, Moiseenko OP, Afiyatullov Sh Sh. Fatty-acid compositions of marine isolates of the actinobacteria Nocardiopsis umidischolae KMM 7036 and Streptomyces sp. KMM 7210. Chem Nat Compd. 2012:48:299-300.

27. Geng P, Bai G, Shi Q, Zhang L, Gao Z, Zhang Q. Taxonomy of the Streptomyces strain ZG0656 that produces acarviostatin $\alpha$-amylase inhibitors and analysis of their effects on blood glucose levels in mammalian systems. J Appl Microbiol. 2009;106:525-533.

28. Lanoot B, Vancanneyt M, Cleenwerck I, et al. The search for synonyms among streptomycetes by using SDS-PAGE of whole-cell proteins. Emendation of the 
species Streptomyces aurantiacus, Streptomyces cacaoi subsp. cacaoi, Streptomyces caeruleus and Streptomyces violaceus. Int J Syst Evol Microbiol. 2002;52: $823-829$.

29. Savrav Kumar, Kannabiran Krishnan. Cytotoxicity and antioxidant activity of 5 (2, 4-dimethylbenzyl) pyrrolidin-2-one extracted from marine Streptomyces VITSVK5 spp. Saudi J Biol Sci. 2012;19:81-86.
30. Thenmozhi Mohankumar, Sindhura Siva, Kannabiran Krishnan. Characterization of antioxidant activity of Streptomyces species VITTK3 isolated from Puducherry Coast, India. J Adv Sci Res. 2010;1:46-52.

31. Zhong Kai, Gao Xia-Ling, Xu Zheng-Jun, et al. Antioxidant activity of a nove Streptomyces strain Eri12 isolated from the rhizosphere of Rhizoma curcumae Longae. Curr Res Bacteriol. 2011;4:63-72. 